\title{
Evaluating Knowledge, Awareness and Behaviour Among Dental Interns Regarding Ergonomics in Dentistry: A Cross- Sectional Survey
}

\author{
REBECCA ANDREW ${ }^{1}$, SONIA NARANG ${ }^{2}$, SRISHTI AGGARWAL ${ }^{2}$, THONGAM S. *3
}

INTRODUCTION: Musculoskeletal disorders (MSDs) are one of the main reasons that force dentists to retire early from their practice. AIM: To assess the knowledge, awareness and behaviour among dental Interns in central and southern India regarding Ergonomics in Dentistry

MATERIALS AND METHOD: This cross-sectional study collected data using a questionnaire (pre-tested and pre-validated) amongst dental interns studying in various dental colleges in and around Central India. Participation in the study was voluntary and the questionnaire was divided into 4 sections with a total of 22 close ended questions. Data was anlayzed using SPSS version 21.0 ; descriptive statistics were applied followed by the unpaired samples t-test, Pearson's correlation coefficient and multivariate logistic regression.

RESULTS: The study consisted of 800 dentists, with most having fair knowledge (50.1\%) and awareness (49.7\%) regarding proper ergonomic posture (knowledge scores showed a significant statistical association). Most interns reported that they sometimes (41.5\%) practiced dentistry ergonomically, while only $5.5 \%$ reported doing it always (significant difference, $\mathrm{p}=0.01^{*}$ ). A positive, linear, great strength of association ( $\mathrm{r}$ : + +.7 ) and a significant relationship ( $\mathrm{p}=0.04$ ) was found between knowledge and awareness scores using Pearson's correlation coefficient.

CONCLUSION: Dental awareness programmes are advised to educate dentists about the impending threat of MSDs if dentistry is not practiced ergonomically.

KEYWORDS: Ergonomics, Posture, Pain, Dentists

\section{INTRODUCTION}

In the field or sports, any serious injury can lead to early retirement and the same applies in the field of dentistry. Dentists are passionate about their dental practice; yet improper posture can force them to retire early due to the excessive pressures on palms, arms, back, neck etc. ${ }^{1}$ This same, repetitive improper posture later serves as an occupational hazard for the dentists. ${ }^{2}$ A study reported that approximately $29.5 \%$ dentists reported Musculoskeletal Disorder as the primary reason for their early retirement. ${ }^{3}$

These disorders in the work place as defined as "the disorders to which the work environment contributes significantly or to musculoskeletal disorders that are made worse or longer lasting by work conditions or workplace risk factors". ${ }^{4}$ These MSDs are identified as damages to the human support system of muscles, ligaments, tendons, nerves, blood vessels, bones, and joints, and can occur from a single event or cumulative trauma. ${ }^{5,6}$

The most common musculoskeletal disorder observed among dental clinicians was back-pain, followed by neck pain, a high muscle tension on trapezoids, tendonitis, carpel tunnel syndrome, nerve trapping, early arthrosis, myopia, auditive alterations, etc. ${ }^{7}$ These problems have been shown to have a directly proportional relationship with to the number of practising years of a dentist. ${ }^{8}$

Therefore, it is imperative that budding dentists in dental colleges be taught about the ill effects of having a bad posture and poor work ergonomics. Since interns are eager to start clinical practice after passing out from their dental college, it is important that they follow proper procedures, failing which, they might suffer from the above-mentioned manifestations of Musculoskeletal disorders and force them to retire early from their illustrious career as dental professional. Hence, this study was conducted with the aim to assess the Knowledge, Awareness and Behaviour among dental Interns in central and southern India regarding ergonomics in dentistry.

\section{MATERIALS AND METHODS}

The present study cross-sectional in nature, conducted 
amongst dental interns studying in various dental colleges in and around Central India using convenience sampling from June 2019 to November 2019 after obtaining all necessary approvals (including ethical clearance) prior to start of the study.

Data was collected using a pre-tested and pre-validated questionnaire filled by the interns and before they could answer the questionnaire, the first page informed them of the study objectives and that participation in the study was purely voluntary in nature. The interns were also informed that they could leave answering the questionnaire in between as per convenience.

The questionnaire was divided pre-tested and prevalidated prior to the commencement of the study. It was divided into 4 sections and contained 22 questions (close ended) which took approximately 4-5 minutes to complete.

Data was anlayzed using SPSS version $21.0^{9}$ using descriptive statistics and the unpaired samples t-test, followed by Pearson's correlation coefficient and multivariate logistic regression.

\section{RESULTS}

Of a total of 1000 questionnaires distributed, we received 800 fully filled responses (response rate: $80 \%$ ) which were further analyzed.

\section{Knowledge and awareness and among dental interns regarding proper ergonomic posture (table 1)}

It was observed that most respondents has fair knowledge (50.1\%) and awareness (49.7\%) regarding proper ergonomic posture, with knowledge scores showing a significant statistical association. More respondents showed good knowledge $(25 \%)$ than awareness(19.3\%).

\begin{tabular}{|l|c|c|c|c|} 
& Good & Fair & Poor & $\begin{array}{c}\text { P- } \\
\text { value }\end{array}$ \\
\hline Knowledge & $\begin{array}{c}200 \\
(25 \%)\end{array}$ & $\begin{array}{c}401 \\
(50.1 \%)\end{array}$ & $\begin{array}{c}199 \\
(24.9 \%)\end{array}$ & 0.01 \\
\hline Awareness & $\begin{array}{c}154 \\
(19.3 \%)\end{array}$ & $\begin{array}{c}398 \\
(49.7 \%)\end{array}$ & $248(31 \%)$ & NS \\
\hline
\end{tabular}

Table 1. Knowledge and awareness and among dental interns regarding proper ergonomic posture

Ergonomic practice among dental interns (table 2) The results indicated that most interns only sometimes (41.5\%) practice dentistry ergonomically, while only
$5.5 \%$ reported doing it always. The difference in economic postures was found to be statistically significant.

\begin{tabular}{|c|c|c|}
\hline \multicolumn{1}{|c|}{$\mathbf{n , \%}$} & P-value \\
\hline $\begin{array}{c}\text { Prefer not to } \\
\text { answer }\end{array}$ & $243(30.4 \%)$ & \\
\hline Never & $154(19.3 \%)$ & \\
\hline Sometimes & $332(41.5 \%)$ & O.o1* $^{*}$ \\
\hline Mostly & $26(3.3 \%)$ & \\
\hline Always & $45(5.5 \%)$ & \\
\hline
\end{tabular}

Table 2. Ergonomic practice among Dental Interns

Perceived reasons for musculoskeletal disorders among dentists (table 3)

Most of the common reasons provided by the study respondents for the development of musculoskeletal disorders among dentists was improper visibility (22.5\%), followed by incorrect posture (16.8\%) and Lack of neck/back support (15.5\%) in the second and third place. No significant difference was found between the responses.

\begin{tabular}{|c|c|c|}
\hline & $\mathbf{n}, \%$ & P-value \\
\hline $\begin{array}{c}\text { No Breaks } \\
\text { while doing } \\
\text { patients }\end{array}$ & $202(11.2 \%)$ & \multirow{7}{*}{ NS } \\
\hline $\begin{array}{l}\text { Handpiece } \\
\text { vibration }\end{array}$ & $158(8.8 \%)$ & \\
\hline $\begin{array}{l}\text { Incorrect } \\
\text { Posture }\end{array}$ & $301(16.8 \%)$ & \\
\hline $\begin{array}{l}\text { Improper } \\
\text { visibility }\end{array}$ & $404(22.5 \%)$ & \\
\hline $\begin{array}{c}\text { Lack of } \\
\text { neck/back } \\
\text { support }\end{array}$ & $278(15 \cdot 5 \%)$ & \\
\hline Lack of Exercise & $254(14.1 \%)$ & \\
\hline $\begin{array}{l}\text { Long working } \\
\text { hours }\end{array}$ & 199 (11.1\%) & \\
\hline
\end{tabular}

Table 3. Perceived reasons for musculoskeletal disorders among dentists

Relationship between knowledge and awareness scores (table 4)

A positive, linear, great strength of association $(\mathrm{r}:+0.7)$ and a significant relationship ( $\mathrm{p}=0.04$ ) was found between knowledge and awareness scores using Pearson's correlation coefficient and multivariate linear analysis, while no significant relation was 


\begin{tabular}{|c|c|c|c|c|}
\hline \multicolumn{2}{|c|}{ p-value } & $\begin{array}{c}\text { Correlation } \\
\text { coefficient } \\
\text { (Pearson's) }\end{array}$ & 95\% CI & $\begin{array}{c}\text { Multivariate } \\
\text { Analysis }\end{array}$ \\
\hline Knowledge & Awareness & 0.7 & $0.12-1.2$ & $0.04^{*}$ \\
\hline Behaviour & Awareness & 0.3 & $0.32-2.13$ & NS \\
\hline Knowledge & Behaviour & 0.3 & $0.02-3.12$ & NS \\
\hline
\end{tabular}

Table 4. Relationship between knowledge and awareness scores

observed while analyzing scores of practice with awareness and knowledge and practice scores.

\section{DISCUSSION}

The noble profession of dentistry makes the dental practitioner focus in relieving the patient of his oral discomfort and is willing to risk his own health for the same. This includes less breaks, lesser physical excercise, longer working hours and lesser time for self care. Repetitive small ranges of motion involved in dental practice can lead to occupational hazard(s) and its relief is the primary objective of dental ergonomics. ${ }^{10}$

In the present study, significant differences were observed between knowledge scores $(\mathrm{p}=0.01)$ while awareness scores regarding ergonomics were found to be insignificant. The significant knowledge scores are in agreement to Vyas $\mathrm{K}$ et al.11 and Desai $\mathrm{V}$ et al.12 Good awareness regarding ergonomics was seen only among $19.3 \%$ of dental interns, and the results are in disagreement to Jadhav HC et al.13 Since ergonomics is not included in the Dental Council of India (DCI) curriculum, therefore such differences in scores were observed while comparing the results of the present study with other studies present in the literature.

A majority (41.5\%) of the interns reported that the "sometimes" practice dentistry ergonomically. Similar results were observed by Batra $\mathrm{H}$ et al. (57.5\%).14 In another study documented by Gopinath et al.,15 although $89 \%$ dentists were aware about ergonomics, they observed that only $8 \%$ dentists always follow good ergonomic practices in their clinical practice with prosthodontists were found to have more prevalence of MSDs.

Improper visibility (22.5\%) was the most commonly reported reason for MSD in dental practice by the dental Interns and this is in agreement to Lund, 16 who stresses having an optimum temperature and illumination of the working environment for good ergonomics and prolonged dental practice.
We recommend the inclusion of Ergonomics in dental curriculum so that most future dentists can practice ergonomically and educate their colleagues, too regarding the same.

\section{CONCLUSION}

Based on the results of the present study, it is advised that CDE programmes, workshop, seminars and other educative events should be done from time to time to educate the practising dentists of the impending danger of MSDs before it becomes too late and it the reason for their early retirement.

\section{REFERENCES}

1. Kumar S, Gupta VK, Mishra G. Ergonomics in Dentistry: Really A Practice or Just a Tactics. International Journal of Contemporary Medical Research 2019;6(7): G1-G4. http://dx.doi.org/10.21276/ijcmr.2019.6.7.12

2. Golchha V, Sharma P, Wadhwa J, Yadav D, Paul R. Ergonomic risk factors and their association with musculoskeletal disorders among Indian dentist: a preliminary study using Rapid Upper Limb Assessment. Indian Journal of Dental Research 2014; 25:6.

3. Murphy DC (NYU College of Dentistry, USA). Ergonomics and dentistry. NY State Dent J. 1997 AugSep;63(7):30-4.

4. Gupta A, Bhat M, Mohammed T, Bansal N, Gupta G. Ergonomics in dentistry. Int J Clin Pediatr Dent. 2014 Jan-Apr; 7(1): 30-34. http://dx.doi.org/10.5005/jpjournals-10005-1229

5. Hayes M, Cockrell D, Smith D. A systematic review of musculoskeletal disorders among dental professionals. International Journal of Dental Hygiene. 2009; 7(3):159-65.

6. Abdolalizadeh $\mathrm{M}$, Jahanimoghadam $\mathrm{F}$. Musculoskeletal Disorders in Dental Practitioners and Ergonomic Strategies. Anatomical Sciences 2015;12(4):161-6.

7. Yousef MK, Al-Zain AO. Posture Evaluation of Dental Students. JKAU Med Sci. 2009;16(2):51-68. 
8. Cagnie B, Danneels L, Van Tiggelen D, De Loose V, Cambier D. Individual and work related risk factors for neck pain among office workers: a cross sectional study. Eur Spine J. 2007;16:679-86.

9. IBM Corp. Released 2012. IBM SPSS Statistics for Windows, Version 21.o. Armonk, NY: IBM Corp.

10. Bhagwat S, Hegde S, Mandke L. Prevalence of Musculoskel- etal Disorders among Indian Dentists: A Pilot Survey with Assessment by Rapid Entire Body Northern India. Journal of Dentofacial Sciences 2012;1(2):1-5.

13. Jadhav HC, Vishwakarma PY, Dodamani AS, Kshirsagar MM, Dodamani GA, Naik RG. Awareness Among Dentists Regarding Ergonomics in Dental Practice: A Cross-sectional Survey. Journal of Oral Health and Community Dentistry 2018;12(3):85-9. 14. Batra H, Rajvanshi H, Anshul K, Singh I, Chhabra N, Teja SV. An Estimation of Awareness among Practicing Dentists about Proper Ergonomic Practice and its
Assessment. World Journal of Dentistry 2015;6(1):3944 .

11. Vyas K, Parihaar L, Rajoria K, Arora J, Pandit A, Singh J. Knowledge, Attitude and Behavior towards "ergonomics" among Oral Health Professionals in Jodhpur city, Rajasthan, India. I J Pre Clin Dent Res 2014;1(3):5-9.

12. Desai V, Pratik P, Sharma R, Ergonomics: A must for Dentistry: A cross sectional study in various parts of Implications in Delhi - National Capital Region. Int J Sci Stud. 2015;3(7):70-5.

15. Gopinadh A, Devi KN, Chiramana S, Manne P, Sampath A, Babu MS. Ergonomics and musculoskeletal disorder: As an occupational hazard in dentistry. J Contemp Dent Pract 2013;14:299-303. http://dx.doi.org/10.5005/jp-journals-10024-1317 16. Lund AE. Have you or a member of your staff ever sustained an injury that is unequivocally related to the provision of dental care? J Am Dent Assoc. 2001;132:284.

Cite this article as:

Andrew R, Narang S, Aggarwal S, Thongam S. Evaluating Knowledge, Awareness and Behaviour Among Dental Interns Regarding Ergonomics in Dentistry: A Cross-Sectional Survey. Int Healthc Res J. 2020;4(7):OR1-OR4. https://doi.org/10.26440/IHRJ/0407.10278

AUTHOR AFFILIATIONS: ( ${ }^{*}$ Corresponding Author)

1. MDS (Prosthodontics), Consultant Dental Surgeon, Nasik, Maharashtra, India

2. BDS, Consultant Dental Surgeon, Bhopal, Madhya Pradesh, India

3. MDS (Oral Pathology) and Private Practitioner, Manipur, Imphal, India 